\title{
ESTIMATIVA DA ALTURA DA CAMADA LIMITE CONVECTIVA SOBRE FLORESTA AMAZÔNICA
}

\author{
Francisco Miranda ${ }^{1}$, Cléo Quaresma Dias Junior ${ }^{1}$, Cledenilson Souza ${ }^{1}$, Leonardo D. A. Sá ${ }^{2}$, \\ ${ }^{1}$ Instituto Nacional de Pesquisas da Amazônia \\ ${ }^{2}$ Instituto Nacional de Pesquisas Espaciais-CRA \\ ffarias.uea.edu.br
}

\section{RESUMO}

Estimou-se a altura da camada limite convectiva (CLC) acima da Floresta Amazônica (Caxiuanã). Foram utilizados dados meteorológicos obtidos por radiossondas e dados turbulentos de alta frequência medidos em torre, nas estações seca e úmida. Os resultados mostram que é possível estimar a altura da camada limite convectiva sobre floresta a partir da informação fornecida pelo pico espectral da componente da velocidade do vento na direção do vento médio.

\section{SUMMARY}

The height of the convective boundary layer above the Amazonian forest (Caxiuanã site) has been estimated. Radiosonde data and fast-response turbulent data measured in a tower have been used, for the wet and dry seasons. The results show that it is possible to estimate the height of the convective boundary layer above the forest zone based on the use of the information provided by the spectral peak of wind velocity for the mean wind direction.

\section{INTRODUÇÃO}

A informação sobre a altura da CLC é importante para a obtenção de uma escala de comprimento característica da CLC. Contudo, isto nem sempre é possível. Portanto, é interessante pesquisar métodos que, baseados unicamente em dados medidos em torre, possam estimar a altura da CLC. Isto já foi obtido em várias regiões (Marques Filho, 1999), mas não acima da floresta Amazônica. As características da estrutura da CLC equatorial podem diferir daquelas encontradas em CLCs de latitudes mais elevadas, razão pela qual o presente estudo é plenamente justificado.

\section{MATERIAIS E MÉTODOS}

Foram utilizados dados (Radiossondagens verticais e dados de torre) de dois experimentos no sítio de Caxiuanã, PA: O "Cobra-Pará", nos dias Julianos de 310 a 312 de 2006 e o "CIMELA", no dia Juliano 317 de 2003. A metodologia foi baseada em Liu e Ohtaki (1997). Para estimar a altura da camada limite $z_{i}$, é preciso conhecer os valores da frequência adimensional máxima $\left(\mathrm{n}_{\mathrm{m}}\right)$ e a altura de medição $\mathrm{z}$, do espectro de potência da velocidade do vento, em que o comprimento de onda máximo é dado por:

$$
\lambda_{\mathrm{m}}=\mathrm{z} / \mathrm{n}_{\mathrm{m}}
$$

Da Equação, 1 estima-se a altura da camada limite convectiva, pela Equação:

$$
\left(\lambda_{\mathrm{m}}\right)=\alpha \mathrm{z}_{\mathrm{i}}
$$

em que $\alpha==0,67$ é a constante usada para o presente ajuste. Para o caso de floresta, utilizase o deslocamento do plano-zero, $d$, de tal forma que $z$ deve ser substituído por $z-d$. 


\section{Resultados e discussão}

Mostra-se que é possível estimar a altura da CLC sobre floresta a partir da utilização do pico espectral da componente do vento na direção do escoamento médio, $u$, conforme Tabela 1 e Figuras 1 e 2, nas quais é possível ainda observar que, para o caso de floresta, o melhor ajuste foi obtido para a estação seca.

Provavelmente, as discrepâncias que ocorrem sempre até as 9 Hs, hora local, se devam ao fato de a camada de mistura, que se forma no início da manhã, ainda não ter alcançado a camada residual, incorporando-a. Quando essa camada de mistura atinge a camada residual, formando uma coluna totalmente convectiva, observa-se uma sensível melhora na estimativa de $\mathrm{Zi}_{\mathrm{i}}$.

Tabela 1. Altura da camada limite convectiva medida pela componente média de vento (u) e radiossondagens (s). Erro quadrático médio normalizado (EQMN)

\begin{tabular}{|c|c|c|c|c|c|c|c|c|c|}
\hline \multirow{3}{*}{ hora } & \multicolumn{6}{|c|}{ COBRA PARÁ } & \multirow{2}{*}{\multicolumn{2}{|c|}{$\begin{array}{c}\text { CIMELA } \\
317\end{array}$}} & \multirow{3}{*}{$\underset{8}{Z}$} \\
\hline & \multicolumn{2}{|c|}{310} & \multicolumn{2}{|c|}{311} & \multicolumn{2}{|c|}{312} & & & \\
\hline & $\mathrm{u}$ & $\mathrm{S}$ & $\mathrm{u}$ & S & $\mathrm{u}$ & $\mathrm{S}$ & $\mathrm{u}$ & $\mathrm{s}$ & \\
\hline 6 & 168 & 76 & 133 & 64 & 151 & 40 & 178 & 70 & 0,51 \\
\hline 9 & 231 & 121 & 413 & 78 & 458 & 43 & 388 & 82 & 1,27 \\
\hline 12 & 425 & 229 & 547 & 471 & 647 & 519 & 569 & 396 & 0,12 \\
\hline 15 & 780 & 808 & 631 & 1003 & 836 & 1115 & 853 & 799 & 0,08 \\
\hline
\end{tabular}

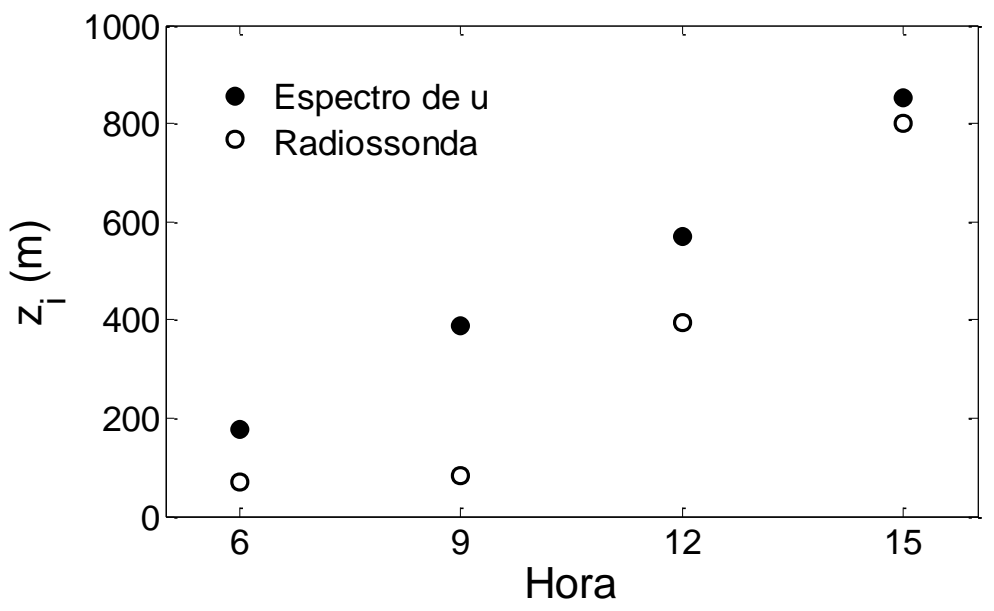

Figura 1. Experimento CIMELA: dia Juliano 317 


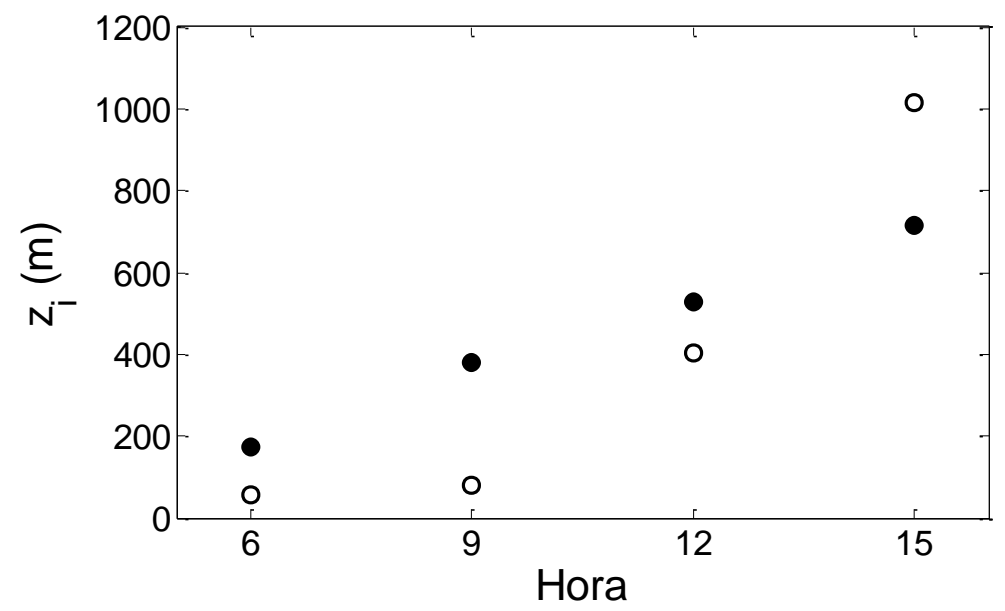

Figura 2. Experimento Cobra Pará: Média dos dias Julianos 310-312

\section{CONCLUSÕES}

Os resultados mostram que é possível estimar a altura da camada de mistura sobre área de floresta tropical a partir de dados de pico espectral da velocidade horizontal do vento.

\section{AGRADECIMENTOS}

Os autores agradecem ao MCT e CNPq/PADCT, através do Instituto do Milênio, Projetos $n^{\circ}$ 62.0056/01-0 e n ${ }^{\circ}$ 620065/01-0 e à FADESP/SECTAM/PRONEX, contrato $n^{\circ}$ 1082, pelo apoio. Leonardo Sá agradece ao CNPq (processo 303.728/2010-8). Francisco Miranda é grato à FAPEAM pela bolsa, ao INPA e UEA e ao projeto LBA.

\section{BIBLIOGRAFIA CITADA}

Liu, X. and Ohtaki, E., "An Independent Method to Determine the Height of the Mixed Layer", Boundary-Layer Meteorology, 85, 3: 497-504, December, 1997.

Marques Filho, E. P., "Alguns aspectos teóricos e experimentais da Camada Limite Superficial acima do Pantanal Matogrossense", INPE, São José dos Campos, SP, Dissertação de Mestrado em Meteorologia, 129 pp., 2000. 